\title{
Cross-modality contrast: Exteroceptive context habituation enhances taste neophobia and conditioned taste aversions
}

\author{
DENIS MITCHELL, WILLIAM WINTER, and TERRIE MOFFITT \\ Psychobiology Program, University of Southern California, Los Angeles, California 90007
}

\begin{abstract}
The relationship between absolute and relative stimulus novelty was examined within the context of the conditioned taste aversion paradigm in which the relative novelty of the conditioned interoceptive stimulus was manipulated by differential exteroceptive context habituation. Rats received similar isolation histories but either 5 or 30 days of habituation to the test environment prior to treatment. One group was administered lithium chloride following saccharin consumption, a second group was administered isotonic saline following saccharin consumption, and a third group was administered saline after water consumption. The animals habituated for 30 days exhibited greater conditioned avoidance and greater neophobic avoidance of saccharin than did animals habituated for only 5 days. The results are interpreted in terms of a cross-modality stimulus contrast effect which implicates context habituation as an important parameter of both taste neophobia and taste aversion learning.
\end{abstract}

The conditioned taste-aversion paradigm is believed, by some (Garcia, Hankins, \& Rusiniak, 1974; Seligman, 1970), to be an exception to traditional learning theories and, by others (Bitterman, 1975; Krane \& Wagner, 1977), to be more or less compatible with current models. A general finding of a variety of traditional avoidance paradigms is that stimulus novelty is of importance in both conditioned and unconditioned avoidance. Several authors (Lubow, Rifkin, \& Alek, 1976; Mitchell, Kirschbaum, \& Perry, 1975; Sheldon, 1969) have distinguished between $a b$ solute and relative stimulus novelty. The former refers to the novelty of a given stimulus compared with the past experience of the subject. The latter refers to the novelty of a stimulus compared with the subject's prior experience with the other stimuli present in the test environment. Lubow et al. (1976) have pointed out that experiments that report effects of novelty on learning, attention, or orienting responses typically do not differentiate between absolute and relative novelty and thereby confound the two. The conditioned taste aversion literature is a pertinent example of this confounding of relative and absolute novelty. Examination of this literature shows that most authors do not specify the amount of time the animals are housed in the testing environments prior to the

The experiment reported in this paper was conducted at Duke University, where the first author was a Visiting Scholar. We want to thank the members of the Animal Behavior Group at Duke, especially Peter Klopfer and John Staddon for their help and encouragement. Requests for reprints should be sent to Denis Mitchell, Psychobiology Program, Department of Psychology, University of Southern California, Los Angeles, California 90007. initiation of their experimental manipulations. Perhaps this is because of the apparent dichotomy between taste or "interoceptive" cues and nontaste or "exteroceptive" cues in their ability to function as the conditioned stimulus in this paradigm. It is the general consensus that taste cues are more readily paired with toxicosis than are nontaste cues (Garcia \& Koelling, 1966). Indeed, this "stimulus specificity" seems so pervasive that it is one of the principal characteristics said to make conditioned taste aversions unique among conditioned avoidance paradigms (Garcia et al., 1974; Seligman, 1970).

Data from several experiments support the view that relative stimulus novelty is an important determinant of unconditioned avoidance behavior. A novel stimulus is more likely to be avoided if all other stimuli present in the test situation are made more familiar by habituation (Mitchell, 1976; Mitchell, Scott, \& Williams, 1973; Sheldon, 1969). Similarly, a novel stimulus is more suitable as a conditioned stimulus than is a familiar stimulus (Dickinson \& Mackintosh, 1978). Several examples can be found in the literature which demonstrate that prior habituation to environmental stimuli present during conditioning will facilitate the acquisition of a conditioned avoidance response (Grant \& Young, 1971; Kurtz, Shafer, \& Hardesty, 1966; Zerbolio, Reynierse, Weisman, \& Denny, 1965). These are probably important conclusions to keep in mind when considering the conditioned and the unconditioned avoidance of novel stimuli. It has been demonstrated that both wild (Barnett, 1958) and laboratory rats (Jennings \& McCutcheon, 1974; Mitchell, 1976) are neophobic; they have a natural tendency to avoid novel stimuli. 
This ability of an unconditioned novel stimulus to elicit a neophobic avoidance response has been shown to be a major component of the poison avoidance behavior of rats (Barnett, 1963; Mitchell, Fairbanks, \& Laycock, 1977). Within the context of the conditioned taste-aversion paradigm, it has similarly been found that the novelty of the taste cue paired with illness is an important determinant of a subsequent conditioned avoidance (Fenwick, Mikulka, \& Klein, 1975; Nachman \& Jones, 1974; Revusky \& Bedarf, 1967).

It has been suggested that the conditioning procedures employed in the conditioned taste-aversion paradigm are superimposed on the preexistent neophobic dispositions of rats toward novel stimuli (Mitchell, 1978). A pertinent example of the synergisms and antagonisms between the habituation of neophobia and conditioning can be seen in the experiments reported by Mitchell et al. (1975). Using a procedure that assumed that the avoidance of a novel stimulus requires a familiar contextual background against which the relative novelty of the stimulus in question can be contrasted, they found that rats that had been habituated to the experimental contextual cues present during conditioning and testing showed a marked increase in both the conditioned and neophobic avoidances of novel exteroceptive cues.

Following their procedure, the present experiment investigated the effects of contextual habituation on both the conditioned and neophobic avoidance of a novel saccharin solution. In this way, the contributions of both absolute and relative stimulus novelty could be compared and evaluated. If conditioned taste aversions were similar to other forms of avoidance conditioning in being sensitive to the relative novelty of the conditioned stimulus, one would expect contextual familiarization to enhance the strength of conditioning: A conditioned taste aversion formed in a novel environment should extinguish faster than one formed in a more familiar environment. Similarly, a given taste stimulus should elicit a greater neophobic avoidance in a familiar environment than in a relatively more novel environment.

\section{EXPERIMENTAL DESIGN}

It has been known for a number of years that if rats are individually housed for protracted periods of time, they often show a characteristic series of physiological and behavioral changes referred to as the "isolation syndrome" (Hatch, Wiberg, Zawidzka, Cann, Airth, \& Grice, 1965). The behavioral changes associated with isolation include reduced activity in an open field (Ader \& Friedman, 1964) and increased neophobia (Morgan, Einon, \& Nicholas, 1975). The physiological changes correlated with isolation include hyperadrenalcorticism (Parker \& Radow, 1974) and increased plasma corticosterone levels (Lovely, Pagano, \& Paolino, 1972).

There is a growing body of evidence which implicates corticosterone or its precursor, ACTH, as a common element in both taste neophobia and conditioned taste aversions (Braveman, 1977; Riley, Jacobs, \& LoLordo, 1976; Smotherman \& Levine, 1978). Though the isolation syndrome usually takes at least 40 days to appear (Hatch et al., 1965), plasma corticosterone levels have been shown to increase by almost $50 \%$ after only 30 days of isolation (Lovely et al., 1972).

The present experiment controls for the possible confounding of isolation stress with apparatus habituation by manipulating contextual habituation and isolation independently. This is achieved by providing the animals with identical isolation experiences but different contextual habituation histories. All of the animals were isolated for 30 days but given differential habituation exposures to the test environment of either 5 or 30 days prior to treatment. In addition to the two treatment conditions usually employed in conditioned taste-aversion experiments (one poisoned, the other given a sham injection after drinking the novel solution), additional groups were included in each habituation condition. Animals in these added groups were presented with the familiar water and given a sham injection. The purpose of these additional groups was to evaluate the role of contextual habituation on the neophobic avoidance of the novel taste cue (Mitchell, 1978).

\section{METHODS}

\section{Subjects}

Sixty male Sprague-Dawley (Charles River) rats, approximately 100 days old at the beginning of the experiment, were used as subjects.

\section{Apparatus}

The entire experiment was conducted in an isolated room used only for this experiment. Lighting was provided by overhead fluorescent tubes that were left on continuously throughout the experiment. The cages used during treatment and testing for all groups were standard stainless steel isolation cages $(24 \times 17.4 \times 18.5 \mathrm{~cm})$ suspended over stainless steel trays covered with a layer of wood shavings. Food (Purina Lab Chow) was supplied from stainless steel hoppers attached to the back of each cage. Room-temperature tap water was provided in a glass bottle, equipped with a neoprene stopper and a stainless steel spout, attached to the front of each cage.

The distinct isolation cages consisted of 30 identical black wooden box cages $(23 \times 23 \times 25 \mathrm{~cm})$ equipped with perforated Plexiglas tops. Food (Purina Lab Chow) was supplied on the floor of each cage, which was covered with a layer of wood shavings. Water was supplied from a water bottle, identical to those used on the standard isolation cages, mounted on the top of each cage. The food and wood shavings were removed and replaced every 4 days.

\footnotetext{
Procedure

On the day they arrived from the supplier, the 60 animals were divided randomly into two equal sets of 30 rats each. The animals
} 
assigned to the 5-day habituation condition were housed individually in the black box cages. The animals assigned to the 30-day habituation condition were housed individually in the standard stainless steel isolation cages. On Day 25, the animals in the 5-day habituation condition were removed from the black box cages at 3:00 p.m. and individually housed in standard isolation cages identical to those occupied by the animals in the 30-day habituation condition. Thereafter, food was provided ad lib, but water consumption for all groups was restricted to a single 30 -min period (3:003:30 p.m.) for the remainder of the experiment. All animals were weighed after the completion of their usual fluid session on Day 30.

\section{Treatment}

On Day 31 (after 5 days of restricted fluid consumption), the 30 animals in each habituation condition were subdivided randomly into three equal groups of 10 rats each and administered one of the following treatments:

Groups 5 P-Sac and 30 P-Sac were presented with a .1\% (w/v) room-temperature sodium saccharin solution and poisoned immediately upon completion of the 30 -min consumption period by a $20-\mathrm{ml} / \mathrm{kg}$ intraperitoneal injection of .15 M lithium chloride.

Groups 5 S-Sac and 30 S-Sac were presented with the saccharin solution and treated with an equivalent volume of isotonic saline $(.15 \mathrm{M})$ immediately after the consumption period.

Groups $5 \mathrm{~S}-\mathrm{W}$ and $30 \mathrm{~S}-\mathrm{W}$ were treated the same as Groups $5 \mathrm{~S}-\mathrm{Sac}$ and $30 \mathrm{~S}$-Sac, except that they were presented with the usual room-temperature tap water before being administered their sham injections.

\section{Testing}

For 8 days following treatment, all subjects were given a 30 -min preference test between water and the $.1 \%(\mathrm{w} / \mathrm{v})$ sodium saccharin solution during the usual 30 -min fluid session. During the habituation and pretreatment portions of the experiment, the single water bottle was always placed in the center of the front of the cage. During testing, the water and saccharin bottles were positioned with the spouts aligned $2 \mathrm{~cm}$ apart, $3 \mathrm{~cm}$ off the floor, in the center of the front of the cage. The saccharin bottles were placed on the right for half of the rats and on the left for the other half. Consumption of water and saccharin $( \pm .1 \mathrm{ml})$ during each 30 -min preference test was recorded for each subject. Saccharin preference was calculated as the proportion of total fluid consumption consisting of saccharin (saccharin consumption divided by saccharin plus water consumption). Testing was done under single-blind conditions; the experimenter collecting the fluid-consumption data had no knowledge of the habituation histories or treatment conditions of the animals.

\section{RESULTS}

The mean saccharin preference scores for all groups on each of the 8 test days are presented in Figure 1. As illustrated, increasing the pretreatment context habituation from 5 to 30 days decreased saccharin preference in each treatment condition. Individual analyses of variance performed on the saccharin preference scores of each test day revealed significant differences across the entire test period [all Fs $(5,54)$ $>24.25$, all ps $<.01$ ]. Newman-Keuls multiple comparison tests $(a=.05)$ between each pair of treatment conditions indicated that the animals that had been habituated to the apparatus for 30 days and poisoned after drinking saccharin (Group 30 P-Sac) showed a greater saccharin avoidance than all other groups on each test day except for the first 3, on which they were not different from the animals in Group 5 P-Sac,

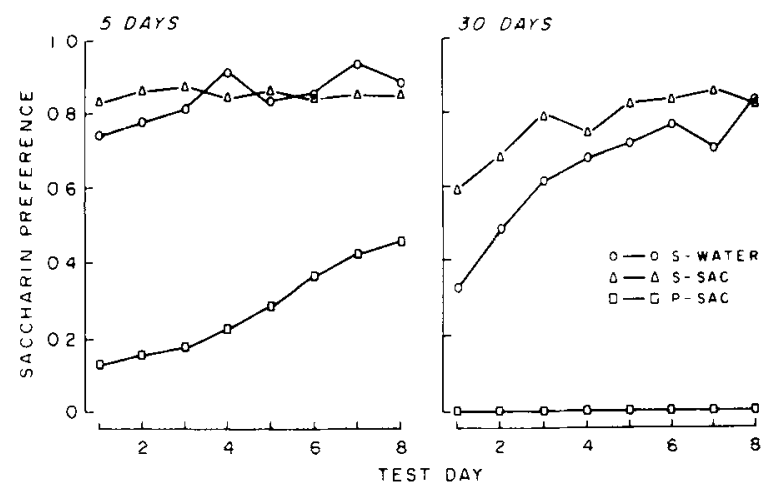

Figure 1. Mean saccharin preference scores for the two sets of three groups given either 5 (left) or 30 (right) days of apparatus habituation prior to treatment. (Figure legends: S-Water = shamwater; S-Sac = sham-saccharin; $\mathbf{P}$-Sac $=$ poison-saccharin.)

which were habituated to the test apparatus for only 5 days before being poisoned after drinking saccharin. Similarly, Group 5 P-Sac was different from all other groups on each test day except for the first 3, on which it was not different from Group 30 P-Sac.

The animals that had been habituated to the apparatus for 30 days and had subsequently been given a saline injection after drinking water (Group $30 \mathrm{~S}-\mathrm{W}$ ) were also significantly different from all other groups on the first 2 test days. Finally, the preference scores of the animals that had been habituated to the apparatus for 30 days before being treated with a sham injection after drinking saccharin (Group S-Sac) were significantly lower than those of the similarly treated group with only 5 days of habituation (Group $5 \mathrm{~S}$-Sac) on the first test day. Total fluid consumption was analyzed on the last habituation day, the treatment day, and the first test day. No significant differences were found. Because all of the animals in this experiment had similar isolation histories but different habituation treatments, these results indicate that isolation stress is not a sufficient explanation for the observed effects.

\section{DISCUSSION}

Taken together, the performance of all three groups in each habituation condition demonstrates that the relative novelty of interoceptive (taste) stimuli is an important determinant of the avoidance behavior characteristic of both taste neophobia and conditioned taste aversions. The ability of context habituation to enhance the avoidance of interoceptive stimuli indicates the existence of a cross-modality stimulus contrast effect in which the avoidance-eliciting properties of a novel taste cue are partially dependent upon the relative novelty of the exteroceptive contextual cues present in the test environment. Insofar as these results are similar to results obtained when 
the relative novelty of an exteroceptive stimulus is manipulated by contextual habituation (Mitchell et al., 1975), they indicate that both classes of stimuli are subject to similar constraints. On the other hand, the present results do not support the view that interoceptive cues are a unique category of stimuli relatively independent of exteroceptive influences (cf. Garcia \& Koelling, 1966; Kalat, 1977).

In addition to providing support for the view that there is an interplay between habituation and conditioning in the taste aversion paradigm (Mitchell, Parker, \& Johnson, 1976; Mitchell, Scott, \& Mitchell, 1977), these experiments confirm recent reports that the exteroceptive environment plays an important modulating role in taste-aversion learning. Rudy, Rosenberg, and Sandell (1977) demonstrated that the taste-familiarity effect can be significantly disrupted by exposing rats to novel exteroceptive stimulation prior to conditioning with a familiar taste. Similarly, Archer, Sjödén, Nilsson, and Carter (1979) reported that conditioned taste aversions show context specificity; rats that formed a conditioned avoidance in one environment extinguished much faster in another. Because the same environment was employed throughout conditioning and testing, the present results are probably more applicable to the typical conditioned taste-aversion experiment than is either of the above reports. Though the experiments from both of these laboratories were directed at different questions and employed different procedures, their conclusions are compatible with the results of the present experiment.

A final implication of the present experiment is that experimenters attempting to evaluate taste neophobia and the role it plays in the conditioned taste-aversion paradigm should distinguish between the relative and the absolute novelty of the stimuli employed. Indeed, many of the disagreement concerning the role of neophobia in this paradigm may be due to the general failure of researchers to distinguish between the two (cf. Garcia, 1978; Mitchell, 1978; Revusky, 1978; Smith, 1978).

\section{REFERENCES}

Ader, R., \& Friedman, S. B. Social factors affecting emotionality and resistance to disease in animals: IV. Differential housing, emotionality and Walker 256 carcinosarcoma in the rat. Psychological Reports, 1964, 15, 535-541.

Archer, T., Suödén, P. O., Nilsson, L. G., \& Carter, N. Role of exteroceptive background context in taste-aversion conditioning and extinction. Animal Learning \& Behavior, 1979, 7, 17-22.

Barnett, S. A. Experiments in "neophobia" in wild and laboratory rats. British Journal of Psychology, 1958, 49, 195-201.

Barnett, S. A. The rat: $A$ study in behavior. London: Methuen, 1963.

Bitterman, M. E. The comparative analysis of learning. Science, $1975,188,699-709$.
Braveman, N. What studies on pre-exposure to pharmacological agents tell us about the nature of the aversion-inducing agent. In L. M. Barker, M. Best, \& M. Domjan (Eds.), Learning mechanisms in food selection. Waco, Tex: Baylor University Press, 1977.

Dickinson, A., \& Mackintosh, N. J. Classical conditioning in animals. Annual Review of Psychology, 1978, 29, 587-612.

Fenwick, S., Mikulka, P. J., \& Klein, S. B. The effect of different levels of pre-exposure to sucrose on the acquisition and extinction of a conditioned aversion. Behavioral Biology, 1975, 14, 231-235

Garcia, J. Mitchell, Scott, and Mitchell are not supported by their own data. Animal Learning \& Behavior, 1978, 6, 116.

Garcia, J., Hankins, W. G., \& Rusiniak, W. Behavioral regulations of the milien interne in man and rat. Science, 1974, $185,824-831$.

Garcia, J., \& Koelling, R. A. Relation of cue to consequence in avoidance learning. Psychonomic Science, 1966, 4, 123-124.

Grant, M., \& Young, D. The effects of preexposure to a learning apparatus. Behavior Research Methods \& Instrumentation, 1971, 3, 251-252.

Hatch, A. M., Wiberg, G. S., Zawidzka, Z., Cann, M., Airth, J. M., \& GRice, H. C. Isolation syndrome in the rat. Toxicology and Applied Pharmacology, 1965, 7, 737-745.

Jennings, W. A., \& McCutcheon, L. E. Novel food and novel running wheels: Conditions for inhibition of sucrose intake in rats. Journal of Comparative and Physiological Psychology, 1974, 87, 100-105.

Kal,at, J. W. Biological significance of food aversion learning. In N. W. Milgram, L. Krames, \& T. M. Alloway (Eds.), Food aversion learning. New York: Plenum Press, 1977.

Krane, R. V., \& WaGner, A. R. Taste aversion learning with a delayed shock US: Implications for the "generality of the laws of learning." Journal of Comparative and Physiological Psychology, 1977, 88, 882-889.

Kurtz, P. A., Shafer, J. N., \& Hardesty, V. A. Adaptation to the conditioning chamber in multi-session avoidance learning. Psychonomic Science, 1966, 6, 225-226.

Lovely, R. H., Pagano, R. R., \& Paolino, R. M. Shuttle-box avoidance performance and basal corticosterone levels as a function of duration of individual housing in rats. Journal of Comparative and Physiological Psychology, 1972, 82, 331-335.

Lubow, R. E., Rifin, B., \& Alek, M. The context effect: The relationship between stimulus preexposure and environmental preexposure determines subsequent learning. Journal of Experimental Psychology: Animal Behavior Processes, 1976, 90, 190-197.

Mitchell, D. Experiments on neophobia in wild and laboratory rats: A reevaluation. Journal of Comparative and Physiological Psychology, 1976, 90, 190-197.

Mitchell, D. The psychological vs, the ethological rat: Two views of the poison avoidance behavior of the rat compared. Animal Learning \& Behavior, 1978, 6, 121-124.

Mitchell, D., Fairbanks, M., \& Laycock, J. D. Suppression of neophobia by chlorpromazine in wild rats. Behavioral Biology, 1977, 19, 309-323.

Mitchell, D., Kirschbaum, E. H., \& Perry, R. L. Effects of neophobia and habituation on the poison-induced avoidance of exteroceptive stimuli in the rat. Journal of Experimental Psychology: Animal Behavior Processes, 1975, 104, 47-55.

Mitchell, D., Parker, L. F., \& Johnson, R. Absence of a generalization decrement in the poison-induced avoidance of interoceptive stimuli in the rat. Physiological Psychology, 1976, 4, 121-123.

Mitchell, D., Scott, D., \& Mitchell, L. K. Attenuated and enhanced neophobia in the taste-aversion "delay of reinforcement" effect. Animal Learning \& Behavior, 1977, 5, 99-102.

Mitchell, D., Scott, D. W., \& Williams, K. D. Container neophobia and the rat's preference for earned food. Behavioral Biology, 1973, 9, 612-624. 
Morgan, M. J., Einon, D. F., \& Nicholas, D. The effects of isolation rearing on behavioral inhibition in the rat. Quarterly Journal of Experimental Psychology, 1975, 27, 615-634.

NaChman, M., \& JONES, D. R. Learned taste aversions over long delays in rats: The role of learned safety. Journal of Comparative and Physiological Psychology, 1974, 86, 949-956.

Parker, L. F., \& Radow, B. L. Isolation stress and volitional ethanol consumption in the rat. Physiology \& Behavior, 1974, 12, 1-3.

Revusky, S. H. Reply to Mitchell. Animal Learning \& Behavior, 1978, 6, 119-120.

Revusky, S. H., \& Bedarf, E. W. Association of illness with prior ingestion of novel foods. Science, 1967, 155, 219-220.

Riley, A., JacoBs, W. J., \& LoLordo, V. M. Drug exposure and the acquisition and retention of a conditioned taste aversion. Journal of Comparative and Physiological Psychology, 1976, 90, 799-807.

Rudy, J. W., Rosenberg, L., \& Sandell, J. H. Distuption of a taste familiarity effect by novel exteroceptive stimulation.
Journal of Experimental Psychology: Animal Behavior Processes, $1977,3,26-36$.

Seligman, M. E. P. On the generality of the laws of learning. Psychological Review. 1970, 77, 406-418.

Sheldon, A. B. Preference for familiar versus novel stimuli as a function of the familiarity of the environment. Journal of Comparative and Physiological Psychology, 1969, 67, 516-521.

Smith, J. C. Comment on paper by Mitchell, Scott, and Mitchell. Animal Learning \& Behavior, 1978, 6, 117-118.

Smotherman, W. P., \& Levine, S. ACTH and ACTH 4 -10 modification of neophobia and taste aversion responses in the rat. Journal of Comparative and Physiological Psychology, 1978, 92, 22-33.

Zerbolio, D. J., Reynierse, J. H., Weisman, R. G., \& Denny, M. R. Pseudoconditioning. Journal of Comparative and Physiological Psychology, 1965, 59, 271-274.

(Received for publication November 13, 1979; revision accepted May 8,1980 .) 